\title{
DETECTION OF ANTIBODIES AGAINST BOVINE HERPES VIRUS 1, BOVINE VIRAL DIARRHEA VIRUS AND BOVINE RESPIRATORY SYNCITIAL VIRUS IN EARLY AND ULTRA-EARLY WEANED BEEF CALVES
}

\author{
${ }^{1}$ Diego Daniel Gonzalez, ${ }^{2}$ Juan Sebastian Vittone, ${ }^{2}$ Martin Lado, ${ }^{2}$ Andrea Biolatto, \\ ${ }_{1,3}$ Marina Valeria Mozgovoj,,${ }^{1,3}$ Alejandra Ferella, ${ }^{1}$ Ayelen Sammarruco, \\ ${ }^{1,3}$ Silvina Maidana, ${ }^{1,3}$ Sonia Alejandra Romera and ${ }^{1,3}$ María Jose Dus Santos \\ ${ }^{1}$ Instituto de Virología, CICVyA, INTA, Castelar, Buenos Aires, Argentina \\ ${ }^{2}$ Estación Experimental Agropecuaria Concepción del Uruguay, INTA, Entre Ríos, Argentina \\ ${ }^{3}$ CONICET, Buenos Aires, Argentina
}

Received 2013-10-15, Revised 2013-10-28; Accepted 2013-10-29

\begin{abstract}
Bovine respiratory disease is the leading cause of morbidity and mortality in weaned calves. In Argentina, two weaning practices have been implemented. In the early weaning, the calf is removed from the cow at 60-70 days of age while in ultra-early weaning the calf is weaned at 30-45 days of age. The purposes of both systems is to improve cow body condition, calf performance, conception rates and forage availability for the cow. In this study we evaluated the antibody response against BVDV and BoHV1 in early and ultraearly weaned calves that had received a conventional vaccination schedule (first dose at weaning and a booster 21 days post-weaning). Passively acquired immunity may provide protection against disease caused by these viruses. The presence of antibodies against BRSV, a virus that was not present in the vaccines used, was also evaluated as an indirect indicator of viral circulation in the herd. At the time of vaccination, calves presented a wide range of maternally-derived antibody titers. Vaccination against BoHV-1 did not evoke seroconvertion and antibody titers continued to decay throughout the experience. After vaccination, seroconversion to BVDV could be detected in calves with low antibody titers, while higher antibody titers exerted an inhibitory effect of the active humoral response.
\end{abstract}

Keywords: Weaning, Bovine Respiratory Disease, Maternal Antibodies, Vaccines

\section{INTRODUCTION}

In beef herds, calves remain with their cows until they are weaned, which traditionally occurs at six to seven month of age.

Weaning is an inherent husbandry practice in cowcalf beef production systems that imposes physical, psychological and nutritional stressors on calves (Lynch et al., 2010b).

In Argentina, two systems have been implemented for weaning. Early weaning involves the removal of the calf from the cow at 60-70 days of age while in ultra early weaning the calf is weaned at 30-45 days of age.
The purposes of both systems are to improve cow body condition, calf performance, conception rates and forage availability for the cow.

The early weaning of calves would greatly reduce calf-rearing costs by decreasing feed and labor expenditures (Hulbert et al., 2011). The increased nutrient and energy demand in lactanting cows associated with lactation can generate to lose body condition. Early and ultra-early weaning managements eliminate these requirements and cows are able to maintain or increase body condition. In addition, they have a greater opportunity to increase the pregnancy rate, since resumption of postpartum ovarian cyclicity is Corresponding Author: Diego Daniel Gonzalez, Instituto de Virología, CICVyA, INTA, Castelar, Buenos Aires, Argentina 
closely related to body condition at partum and the nutritional balance post partum.

Following weaning, dry cows will eat less forage than lactanting ones, further reducing the demand placed on the pasture, which can enhance sustainability and forage production.

It has also been determined that ultra-early weaning is an advantageous management due to the lower levels of cortisol in the calves at that age. Moreover, breaking the bond between the cow and calf appears to be easier at 3045 days post partum than six month later (Valerio, 2007).

By weaning early and providing a highly nutritious diet to ensure a suitable ruminant development, calves can reach their growth potential up to $30 \%$ (Galli et al., 2008; Valerio, 2007).

Weaned calves undergo a transition from a monogastric to a ruminant animal, they have almost undeveloped rumens and high quality nutrient requirement; for that reason, they can not feed only forage. An abrupt change from a liquid diet, specifically milk supply form the mother, to a solid food intake could trigger physiological alterations which may result in negative consequences if they are not properly managed. The use of a calf starter is a crucial link to proper ruminal development and successful weaning, since intake of dry feed initiates rumen development. Early and ultra-early weaned calves became ruminant animals at an earlier age and this management results in an increased calf performance.

Following abrupt weaning, beef calves exhibit distress behaviors (Haley et al., 2005; Price et al., 2003) with alterations in hormonal mediators of stress (Blanco et al., 2009) and immune function (Hickey et al., 2003; Arthington et al., 2008; 2005; Lynch et al., $2010 \mathrm{a} ; 2010 \mathrm{~b}$ ) evident up to seven days post-weaning.

Lynch et al. (2010b; 2012), showed that weaning together with movement of beef calves from a pasture environment to a housing environment elicited transient neutrophilia, impaired neutrophil phagocytic function, decreased peripheral lymphocyte count and altered immunophenotypes. These results suggested that there was a greater transitory reduction in immune function at housing in abruptly weaned than non-weaned beef calves (Lynch et al., 2010b; 2012).

Moreover, weaning is considered to be a predisposing factor to Bovine Respiratory Disease (BRD) (Callan and Garry, 2002; Snowder, 2009). This syndrome has a complex and multifactorial etiology that can be divided into three major categories: Environmental factors, physiological stress and infection factors (Stilwell et al., 2008; Richeson et al., 2012). BRD is an important disease both during pre-weaning period and shortly after weaning and the leading cause of morbidity and mortality in weaning calves.

The respiratory viruses commonly responsible for BRD include bovine herpes virus 1 (causing agent of Infectious Bovine Rinotracheitis or IBR), Bovine Respiratory Syncitial Virus (BRSV), Bovine Viral Diarrhea Virus (BVDV) and Para-Influenza Virus (PI3) (Taylor et al., 2010a). All these viruses are known to be involved in BRD solely or in synergism with other and bacteria.

To ensure the health and well being of early weaned claves, a common practice in beef herds is the vaccination of calves against respiratory viruses at weaning in order to minimize BRD. However, the use of vaccination for the control of BRD in animals on arrival to pens still controversial (Ellis, 2001).

Calves are born agammaglobulinaemic and depend strongly on ingestion of colostum for survival. In addition, the specific and non-specific immune systems are immature in newborn calves, making them especially vulnerable to infections during the first weeks of life.

Passively acquired immunity may provide protection against disease caused by BoHV1, BVDV and BRSV (Belknap et al., 1991; Bolin and Ridpath, 1995; Howard et al., 1989; Mechor et al., 1987). However, young calves do not produce specific Antibodies (Ab) after vaccination in the presence of maternal antibodies. For this reason it is commonly believed that maternal antibodies can interfere with the efficacy of vaccination.

In this study the efficacy of a conventional vaccination program in weaned calves was evaluated. Calves were vaccinated with a commercial vaccine containing BVDV, BoHV1, PI3, Haemophilus somnus, Moraxela bovis, Pasteurella multocida and Pasteurella haemolytica as immunogens. Specific Ab against BVDV, BoHV1 and BRSV (a virus not included in the vaccine) were determined in sera from beef calves that had been early and ultra-early weaned.

\section{MATERIALS AND METHODS}

\subsection{Animals}

The experience was conducted in Concepción del Uruguay INTA's Experimental Station (32 29'28'S; $58^{\circ} 20^{\prime} 49^{\prime \prime} \mathrm{W}, 25 \mathrm{~m}$ above mean sea level), in the province of Entre Rios Province in Argentina.

Fourty eight Hereford and Polled Hereford cows and their respective calves from the Experimental Station were used.

Cows were vaccinated at 30 day prepartum with a commercial vaccine containing inactivated IBR (BoHV1) and BVDV1a, Campylobacter fetus, Leptospira interrogans pomona y Haemophilus somnus. 
These cows were boosted each year. Calves were vaccinated twice, at weaning and 21 days post-weaning (conventional vaccination program) with another commercial vaccine containing inactivated BVDV1a, IBR (HVB-1), PI3, Haemophilus somnus, Moraxella bovis, Pasteurella multocida and Mannheimia haemolytica (Pasteurella haemolytica).

\subsection{Experimental Design}

At weaning, calves were housed in four corrals, each covering a $50 \mathrm{~m}^{2}$ area and with waterers and feed bunks. Calves were allotted to two experimental groups according to their age and weight. The groups were: Early Weaning calves (EW: 66,2 $\pm 9,6$ days old) and

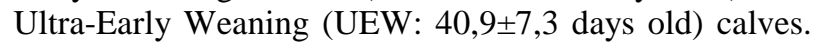
Each group was placed in two pens (12 animals/corral). One corral from each group was immunized with 2 dosis (at weaning and 21 days post-weaning) of a commercial vaccine against BRD. The animals from the other corral of each group remained unvaccinated.

\subsection{Weaning Strategy}

Calves were weaned following the management requirements for EW and UEW according to the Manual of early weaning in beef herds (Galli et al., 2005). All calves were offered ad libitum to a calf ruminal starter (Ruter®, Asociación de Cooperativas Argentinas) and water for 16 days.

Breeding rations (16 to 56 days postweaning) were formulated with whole kernel corn and a comercial concentrate (Starter 40\% Crude Protein, Asociación de Cooperativas Argentinas).

Daily offer was fixed to $2 \%$ of calf weight.

\subsection{Sample Collection}

Peripheral blood samples from cows were collected via jugular venipuncture at 60 and 30 days pre-calving. Serum was collected after centrifugation at $1500 \mathrm{rpm}$ (Hermle) and stored at $-20^{\circ} \mathrm{C}$ until use.

Sera from all calves were obtained as described for cow sampling at 10 days pre-weaning, at weaning (day 0 ) and at 7,21 and 35 days post $2^{\circ}$ immunization.

\subsection{Detection of Antibodies Against BoHV1 by Indirect ELISA}

Total $\mathrm{Ab}$ in bovine serum were determined using an indirect ELISA as described previously (Romera et al., 2000). Briefly, polystyrene microtiter ELISA plates (Immulon 1B, Dynatech Laboratories) were coated with 50ul of positive (concentrated and semi-purified BoHV1 reference strain Los Angeles containing 109 DICT50
$\mathrm{mL}^{-1}$ ) or negative antigen (non-infected MDBK cells) in carbonate buffer of $\mathrm{pH} 9.6$ and incubated for $12 \mathrm{~h}$ at $4{ }^{\circ} \mathrm{C}$. Plates were blocked with $10 \%$ ovoalbumin in PBSTween $200.05 \%$, washed twice and stored at $-20^{\circ} \mathrm{C}$ until use. Samples were tested at 1:4, 1:10 and 1:40 dilutions (Parreno et al., 2010). A peroxidase-labeled affinity purified goat anti-bovine $\operatorname{IgG}(\mathrm{H}+\mathrm{L})$ (Kirkegaard and Perry Laboratories, KPL) in a 1:4000 dilution was used as the conjugate. After each incubation, plates were washed 4 times. The reaction was developed using hydrogen peroxide/2,2B-azino-bis 3-ethylbenzthiazoline6 Sulfonic Acid (ABTS) in citrate buffer ( $\mathrm{pH} \mathrm{5)}$ as the substrate/chromogen system. The Ab titer of each sample was expressed as the $\log 10$ of the reciprocal of the highest serum dilution with a corrected optical density OD405C (OD405 in the positive coated wells minus OD405 in the negative coated wells) greater than the cutoff value of the assay ( $40 \%$ positive control value).

\subsection{Detection of Neutralizing Antibodies (NA) against BVDV by Virus Neutralization Test}

Serum NA from cattle were detected by virus neutralization assay. Briefly, $100 \mathrm{TCID}_{50}$ of BVDV (Singer strain) were co-incubated for $1 \mathrm{~h}$ at $37^{\circ} \mathrm{C}$ with 75 $\mu \mathrm{L}$ of four-fold dilutions of inactivated serum samples. Then, the mixture was added onto $3 \times 10^{4}$ MDBK cells/well. Plates were incubated for $72 \mathrm{~h}$ at $37^{\circ} \mathrm{C}$ under $5 \% \mathrm{CO}_{2}$. Control wells without virus were used for each serum sample in order to discard toxicity.

Serum neutralization titer was considered as the highest serum dilution which inhibited $50 \%$ of viral cytopathic effect. Titers were expressed as the $\log _{10}$ of the highest dilution able to inhibit $100 \mathrm{TCID}_{50}$. A BVDV positive serum from an experimentally infected bovine was used as positive control and a BVDV negative serum from a reference animal was considered as negative control.

\subsection{Detection of NA against BRSV by Virus Neutralization Test}

Serum neutralization assay was carried out as described previously by (Ferella et al., 2012). Inactivated serum samples were fourfold diluted from 1:4 to 1:256. The serum-dilutions were supplied with $100 \mathrm{TCID}_{50}$ of 51908 BRSV strain and incubated for 1 hour at $37^{\circ} \mathrm{C}$ in a $5 \% \mathrm{CO}_{2}$ atmosphere. This mixture was inoculated in duplicate onto MDBK cell monolayers (250000 cells $\mathrm{mL}^{-1}$ ) in 96-well plates. Plates were incubated as above and CPE was observed 5 days post infection. 
Samples were considered positive when no CPE was observed. Antibody titers were expressed as the reciprocal of the maximum dilution in which no $\mathrm{CPE}$ was observed. Samples with titers equal or higher than 4 were considered positive.

\subsection{Statistical Analysis}

Differences in $\mathrm{Ab}$ titers among groups were evaluated by ANOVA under a model of repeated measures throughout time, followed by a general contrast post-ANOVA test.

Statistical significance was assessed at $\mathrm{p}<0.05$ for all comparisons.

\section{RESULTS}

Regarding BVDV and BoHV1, there was not evidence of clinical signs of disease. In addition, there were no BVDV persistently infected calves identified. Passive transfer of maternal antibodies against BVDV and BoHV-1 was detected in all calves.

Table 1 shows the experimental design and the average age and weight of calves according to each treatment.

The distribution of antibodies at weaning for each virus is shown in Table 2. BVDV1a specific antibody titers were relatively low in all groups, with $77 \%$ of total calves presenting a NA titer $\leq 32$. Similarly, $77 \%$ of total calves presented BoHV-1 specific antibody titers $\leq 1.6$. These titers were presumed not to be protective against both BVDV and BoHV-1 (Bolin and Ridpath, 1995).

The mean antibody titers for each group were determined at 10 days pre-weaning, at weaning and 28, 49 and 56 days post weaning, corresponding to 7,21 and 35 days post booster respectively (Fig. 1 and 2).
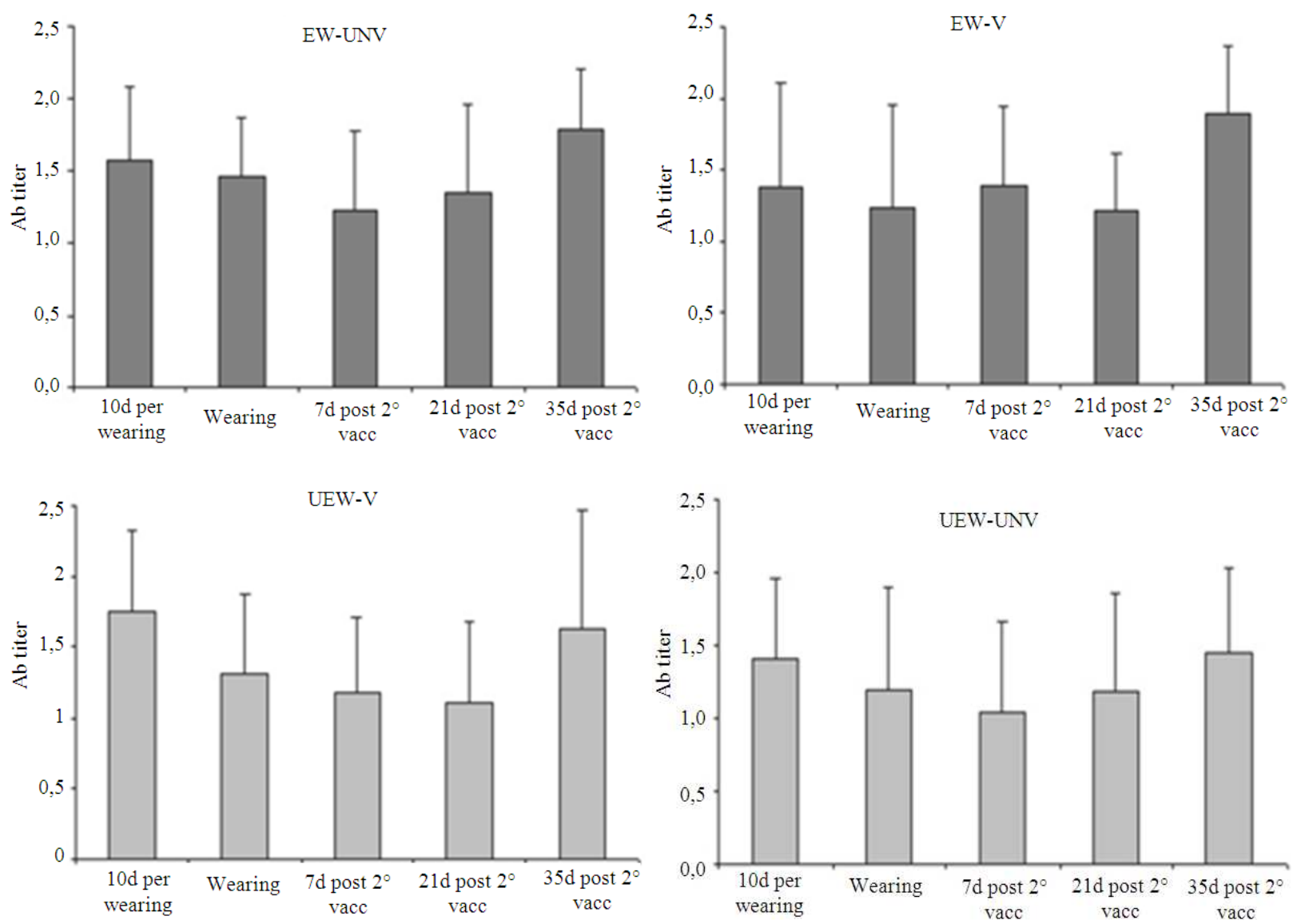

Fig. 1. Antibody response against BVDV Experimental groups (EW-UNV, EW-V, UEW-UNV, UEW-V) were immunized with a commercial vaccine against BRD. At different time points animals were bled and specific BVDV antibodies were evaluated by seroneutralization assay. Each bar represents the average titer of the group 

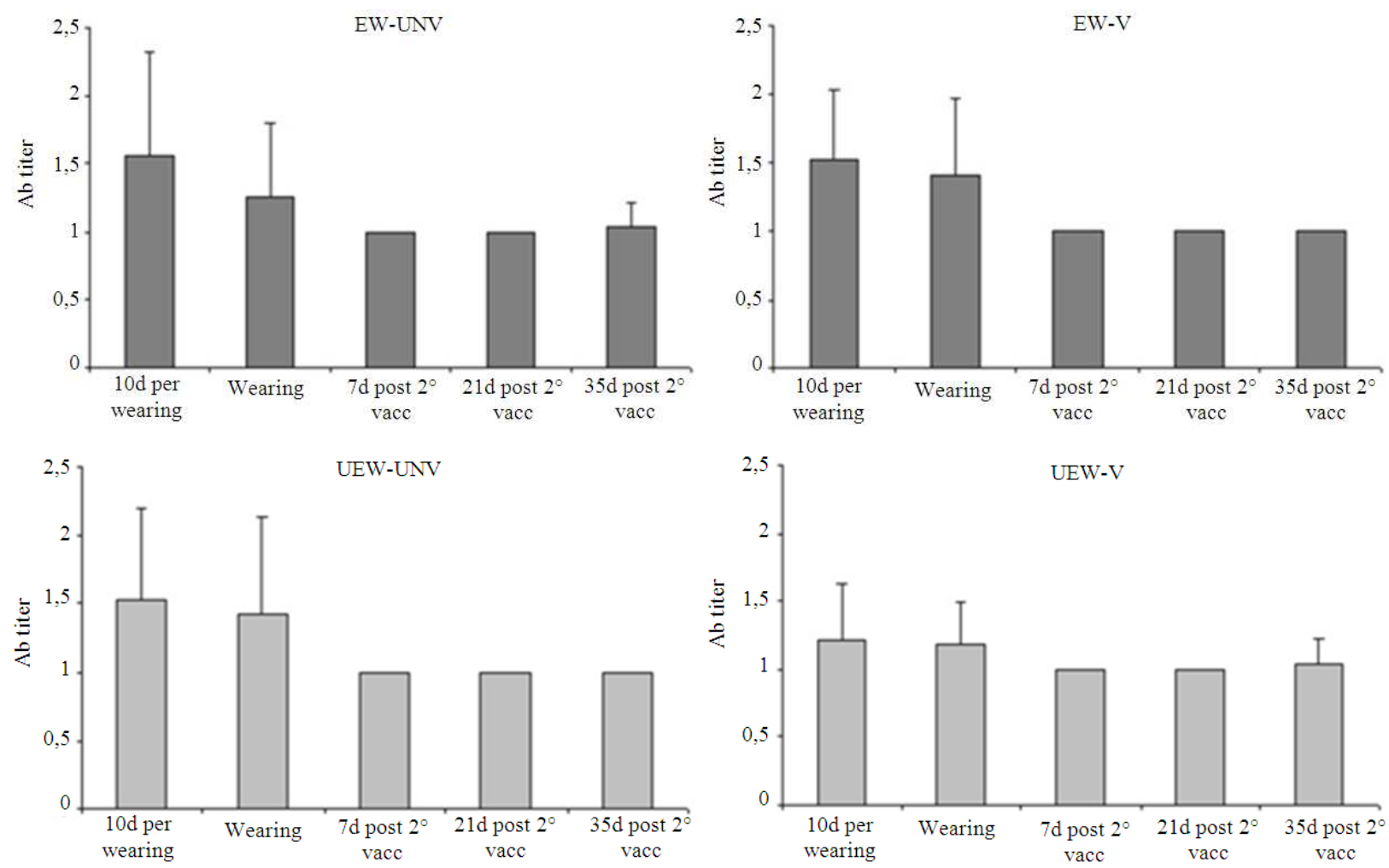

Fig. 2. Antibody response against BoHV1 Experimental groups (EW-UNV, EW-V, UEW-UNV, UEW-V) were immunized with a commercial vaccine against BRD. At different time points animals were bled and specific BoHV1 antibodies were evaluated by ELISA. Each bar represents the average titer of the group

Table 1. Experimental design and average age of cattle

\begin{tabular}{llllll}
\hline Group & Weaning (days of age) & Vaccination & $\mathrm{n}$ & Weight at weaning & Weight at 56 days of age $(\mathrm{kg})$ \\
\hline 1 & Early $(66,6 \pm 10,7)$ & Yes & 12 & $68,1 \pm 7,7$ & $90,7 \pm 12,3$ \\
2 & Early $(65,8 \pm 8,8)$ & No & 12 & $69,8 \pm 9,2$ & $91,7 \pm 14,5$ \\
3 & Ultra-early $(40,3 \pm 7,8)$ & Yes & 12 & $56,2 \pm 9,7$ & $75,4 \pm 16,3$ \\
4 & Ultra-early $(41,4 \pm 7,2)$ & No & 12 & $57,9 \pm 11,6$ & $76,3 \pm 17,1$ \\
\hline
\end{tabular}

Antibody levels detected at 10 days pre-weaning were maternally derived. The BVDV1a mean titers and the antibody range were: 28.51 (4-256) for both EW and UEW group. The BoHV1 mean titers were: $1.54 \pm 0.64$ for EW calves and $1.38 \pm 0.59$ for UEW calves. The BRSV mean titers and the antibody range were: 7.8 (2-32) for the EW group and 16 (2-128) for the UEW group. No significant differences could be observed between early and ultra-early weaned calves at that time indicating that passive transfer of antibodies was homogeneous in all groups for the three viruses evaluated.

The kinetic of antibody response showed that the mean antibody titers did not presented significant differences during the time of study. A slight increase of BVDV1a NA titers could be observed at 35 days post booster in EW-V group, which can be assigned to a few calves that developed high titers of NA (Table 3, Fig. 1).

At 35 days post booster (56 days post-weaning) comparisons between EW-V and EW-UNV animals did not shown significant differences $(\mathrm{p}=0.84)$ Similar results were obtained between UEW-V and UEW-UNV $(p=0.97)$. This result suggested that immunization of early and ultra-early weaned calves with inactivated vaccines for BVDV1a and BoHV1 did not evoke an active antibody response.

Seroconversion after vaccination with BVDV was evaluated at 35 days post booster in each calf. The distribution of antibody titers at weaning (day 0 for immunization) was considered to determine seroconversion (four-fold or greater increase) (Table 4). 
Diego Daniel Gonzalez et al. / American Journal of Animal and Veterinary Sciences 8 (4): 210-219, 2013

Table 2. Distribution of antibody titers to BVDV1a and BoHV1 (number of calves/total calves) at weaning

\begin{tabular}{|c|c|c|c|c|}
\hline \multirow{2}{*}{$\begin{array}{l}\text { BVDV } \\
\text { Antibody } \\
\text { titer at weaning }\end{array}$} & \multicolumn{4}{|c|}{ Experimental group } \\
\hline & UEW- V & UEW- UNV & EW- V & EW- UNV \\
\hline 4 & $2 / 11$ & $4 / 13$ & $3 / 12$ & $1 / 12$ \\
\hline 8 & $3 / 11$ & $2 / 13$ & $3 / 12$ & $2 / 12$ \\
\hline 16 & $0 / 11$ & $0 / 13$ & $0 / 12$ & $1 / 12$ \\
\hline 32 & $3 / 11$ & $4 / 13$ & $4 / 12$ & $5 / 12$ \\
\hline 64 & $2 / 11$ & $0 / 13$ & $0 / 12$ & $3 / 12$ \\
\hline 128 & $1 / 11$ & $3 / 13$ & $1 / 12$ & $0 / 12$ \\
\hline 256 & $0 / 11$ & $0 / 13$ & $0 / 12$ & $0 / 12$ \\
\hline 512 & $0 / 11$ & $0 / 13$ & $0 / 12$ & $0 / 12$ \\
\hline 1024 & $0 / 11$ & $0 / 13$ & $1 / 12$ & $0 / 12$ \\
\hline \multicolumn{5}{|c|}{ BoHV1 antibody titer at weaning } \\
\hline$<1.6$ & $7 / 11$ & $7 / 13$ & $6 / 12$ & $8 / 12$ \\
\hline 1.6 & $4 / 11$ & $2 / 13$ & $2 / 12$ & $1 / 12$ \\
\hline 2.2 & $0 / 11$ & $2 / 13$ & $4 / 12$ & $3 / 12$ \\
\hline 2.8 & $0 / 11$ & $2 / 13$ & $0 / 12$ & $0 / 12$ \\
\hline
\end{tabular}

Table 3. Distribution of antibody titers to BVDV1a and BoHV1 (number of calves/total calves) at day 35 post booster

\begin{tabular}{|c|c|c|c|c|}
\hline \multirow{2}{*}{$\begin{array}{l}\text { BVDV antibody } \\
\text { titer } 35 \text { days } \\
\text { post Booster }\end{array}$} & \multicolumn{4}{|c|}{ Experimental group } \\
\hline & UEW- V & UEW- UNV & EW- V & EW- UNV \\
\hline 4 & $1 / 11$ & $1 / 13$ & $0 / 12$ & $0 / 12$ \\
\hline 8 & $3 / 11$ & $5 / 13$ & $1 / 12$ & $1 / 12$ \\
\hline 16 & $0 / 11$ & $0 / 13$ & $1 / 12$ & $1 / 12$ \\
\hline 32 & $2 / 11$ & $3 / 13$ & $3 / 12$ & $5 / 12$ \\
\hline 64 & $0 / 11$ & $0 / 13$ & $1 / 12$ & $0 / 12$ \\
\hline 128 & $1 / 11$ & $2 / 13$ & $4 / 12$ & $5 / 12$ \\
\hline 256 & $0 / 11$ & $1 / 13$ & $1 / 12$ & $0 / 12$ \\
\hline 512 & $1 / 11$ & $0 / 13$ & $1 / 12$ & $0 / 12$ \\
\hline 1024 & $3 / 11$ & $0 / 13$ & $0 / 12$ & $0 / 12$ \\
\hline \multicolumn{5}{|c|}{ BoHV1 antibody titer at 35 days post booster } \\
\hline$<1.6$ & $11 / 11$ & $13 / 13$ & $12 / 12$ & $11 / 12$ \\
\hline 1.6 & & & & $1 / 12$ \\
\hline \multicolumn{5}{|l|}{2.2} \\
\hline 2.8 & & & & \\
\hline
\end{tabular}

Table 4. Seroconversion at 35 days post booster (number of calvesl serconverted/total calves)

\begin{tabular}{lllll}
\hline $\begin{array}{l}\text { BVDV } \\
\text { antibody titer } \\
\text { at weaning }\end{array}$ & Experimental group & & \\
\hline 4 & UEW- V & UEW- UNV & EW- V & EW- UNV \\
8 & $2 / 2$ & $0 / 4$ & $3 / 3$ & $0 / 1$ \\
16 & $1 / 3$ & $1 / 2$ & $2 / 3$ & $0 / 2$ \\
32 & - & - & - & $0 / 1$ \\
64 & $2 / 3$ & $0 / 4$ & $2 / 4$ & $2 / 4$ \\
128 & $0 / 2$ & - & - & $0 / 3$ \\
256 & $0 / 1$ & $0 / 3$ & $0 / 1$ & - \\
512 & - & - & - & - \\
1024 & - & - & - & - \\
\hline
\end{tabular}

Table 5. Distribution of antibody titers to BRSV (number of calves/total calves)

\begin{tabular}{lll}
\hline & Experimental group & \\
BRSV antibody & -------- \\
titer at weaning & EW & UEW \\
\hline 2 & $7 / 24$ & $2 / 24$ \\
4 & $2 / 24$ & $7 / 24$ \\
8 & $5 / 24$ & $2 / 24$ \\
16 & $2 / 24$ & $8 / 24$ \\
32 & $5 / 24$ & $0 / 24$ \\
64 & $2 / 24$ & $3 / 24$ \\
128 & $1 / 24$ & $2 / 24$ \\
BRSV antibody titer 56 days post & \\
2 & $14 / 24$ & $17 / 24$ \\
4 & $5 / 24$ & $3 / 24$ \\
8 & $3 / 24$ & $0 / 24$ \\
16 & $2 / 24$ & $2 / 24$ \\
32 & $0 / 24$ & $0 / 24$ \\
64 & $0 / 24$ & $2 / 24$ \\
\hline
\end{tabular}

In the UEW and EW groups 5 out of 11 and 7 out of 12 calves, respectively, showed seroconversion to BVDV after two doses of the vaccine. These vaccinated calves presented at weaning antibody titers that ranged from 4 to 32 . Higher antibody titers prevented seroconversion after vaccination in calves from both groups.

Antibody titers to BoHV1, in all groups evaluated, were lower at 35 days post booster than at weaning and no animals showed seroconversion to that virus (data not shown).

Specific antibodies against BRSV were also tested since that virus is involved in BRD but it was not included in the vaccines used in this study (Table 5). At weaning the Ab titers in both EW and UEW calves ranged from 2 to 128 , with more than $80 \%$ of animals presenting an $\mathrm{Ab}$ titer less than 32. The geometric mean titers and the antibody range were 9.51 (2-128) and 11.99 (2-128) for EW and UEW groups, respectively. No significant differences were found between both groups at that time $(p=0.82)$. These Abs were supposed to be maternally transferred and declined to very low levels at 56 days post weaning. Calves with $\mathrm{Ab}$ titers of 64 or higher at weaning showed $\mathrm{Ab}$ titers that ranged from 16 to 64 at 56 days post weaning, while calves with Ab titers lower than 64 became seronegative at 56 after weaning. At that time there were no significant differences between EW and UEW groups $(\mathrm{p}=0.85)$ (mean titer for EW group: 3.27; mean titer for UEW: 3.46). Seroconversion due to BRSV infection could not be observed in any calves. 


\section{DISCUSSION}

The impact of early weaning of calves on the reproductive performance of cows has been demonstrated in the last thirty years under research and commercial conditions in Argentina and other countries (Galli et al., 2008).

Early and ultra early weaning implementation has shown to increase the reproductive efficiency, accelerate rebreeding of the dam postpartum and thus increasing pregnancy rates. Therefore, as weaning practices will probably be widely applied, to perform a correct nutritional and sanitary management of weaned calves is a critical issue for the success of the practice.

Respiratory disease in weaning calves is the leading cause of morbidity and mortality. The presence of antibodies against BRD pathogens has been found to be protective, so it would seem intuitive that immunization would be beneficial (Taylor et al., 2010b), especially when the moments of important immunity suppression associated with these viruses can be foreseen, such as during the weaning and grouping of young animals from different herds. However, the use of vaccination for the control of BRD in animals on arrival to feed-lots is still controversial (Ellis, 2001) and the economic benefit of vaccination against BRD is not fully demonstrated. Much of the failure of vaccination may lie in timing of administration, failure of stressed calves to respond properly to vaccination, the multifactorial nature of BRD and the increased susceptibility of stressed calves to all pathogens.

In this study we evaluated the antibody response against BVDV1a and BoHV1 in weaned calves that have received a conventional vaccination schedule (first dose at weaning and booster 21 days post-weaning). The presence of $\mathrm{Ab}$ against BRSV, a virus not present in the vaccines used, was also evaluated as an indirect indicator of viral circulation in the herd.

Pregnant cows used in this study were 5 to 6 years old and had been previously vaccinated once or more times according to each cow's age. They had antibodies against the BRD's viruses that could have been due to vaccination or natural infection. Specific colostral IgG1 absorbed by the neonate during the first hours of life would have been mainly transferred intact across the small intestinal absorptive epithelium into the calf circulation. After colostrum intake, maternal antibodies could be detected in all calves. However, colostral antibodies levels measured 10 days before weaning and at weaning were heterogeneous in both groups (EW and UEW); in addition, less than $20 \%$ of calves were expected to have antibody titers capable of protecting against infection. Thus, at the time of vaccination, calves presented a wide range of maternally-derived antibody titers. The duration of this passively derived immunity is dependent on the amount of antibodies ingested, absorbed and the rate of decay. Antibody titers usually decay to a level still high enough to block the active response to vaccination, but not high enough to protect from viral infection. This situation creates a window of susceptibility to viral infections (Chase et al., 2008).

While passive immunity provides protection against $\mathrm{BRD}$, this immunity could also block the development of serum antibodies when immunogens are given to calves which have maternal antibodies. However, other studies have shown than some immunogens induce immunologic memory that is not susceptible to maternal antibody regulation (Endsley et al., 2003; 2004; Ellis et al., 1996; Lemaire et al., 2000; Platt et al., 2009).

Calves used in this study showed low titers of colostral antibodies against BoHV1, no seroconversion could be observed after vaccination and the antibody levels continued to decay throughout the experience. This could be due to a failure in the vaccine used.

When antibody levels against BRSV were analyzed at weaning, a range of antibody titers could be observed but with few animals showing Ab titers of 64 or higher (3 animals in the EW and 5 animals in the UEW group). These animals remained seropositive at 56 days post weaning with antibody titers that ranged from 16 to 64 . On the other hand, calves with antibody titer of 32 or lower at weaning became seronegative at the end of the experience. It is important to note that no significant differences were observed between both weaning managements.

BRSV specific colostral antibodies detected in calves indicated that the cow had been infected before; however, calves were not infected throughout the study.

The low titer of colostral antibodies against BRSV detected in EW and UEW calves, pose the need to include that viral agent in the vaccination schedule for both the cow before calving and the calf.

Given that animals were not vaccinated against $\mathrm{BRSV}$, these results indicate that BRSV is probably widespread and may be contributing to respiratory disease in beef herds.

After immunization, seroconversion to BVDV could be detected in calves with low antibody titers (less than 32), while higher antibody titers exerted an inhibitory effect of the active humoral response.

The results of this study are in agreement with those reported by Fulton et al. (2004). In their study, the 
authors found evidence that the maternal immunity had blocked antibody production, even when the calves received two doses of the vaccine. That effect was more notorious in calves with high maternallyderived antibody levels.

It has been reported that immunization of calves with maternal antibodies with an inactivated vaccine for BoHV1, BVDV and PI3 or with MLV BoHV vaccine might prime for a secondary response after a second dose of the vaccine (Ellis et al., 1996; Fulton et al., 2004). In concordance with that finding, it has been proposed that calves with maternal antibodies could develop protective cell-mediated immunity (T-cell) after vaccination which may protects them against viral challenge (Platt et al., 2009; Vangeel et al., 2007). In a recent study Woolums et al. (2013) have shown that the immune response of calves following administration of a 7-way MLV booster vaccination for BRD at weaning was not affected by either the calf's age or the route of priming vaccination (Woolums et al., 2013). In that study, calves failed to develop a detectable immune response after receiving a priming vaccination in the face of maternal antibodies.

In the present work, transfer of passive immunity from the cow to the calf was efficient. However, a wide range of colostral antibody titers could be observed in calves 10 days pre-weaning. In consequence, the calf's age when maternally-derived antibodies do not longer protect against disease or interfere with vaccination was variable. At weaning, when calves are immunized, they may have high, moderate or low antibody titers or they can be seronegative. Under this situation, the design of a unique vaccination program so as to induce protective immunity to all calves becomes a very difficult issue.

A strategy to improve immunity of these calves managed under non-conventional weaning practices would be to enhance the specific immune response in the cow with the purpose of increasing the passive immunity to be transfer to the calf.

Incrementing the number of doses of vaccine and starting vaccination at the earliest possible time may also overcome that difficulty (Fulton et al., 2004), since animals with low colostral antibodies at weaning would respond to the first immunization, while calves with higher colostral antibodies at weaning would seroconvert after the second or third vaccination. However, in beef herds, multiple immunizations of calves are difficult to manage.

These management strategies should be complemented with the screening of calves' immunity to assess the efficacy of the vaccination program. Much of the failure of vaccination may lie in timing of administration, failure of stressed calves to respond properly to vaccination, the multifactorial nature of BRD and the increased susceptibility of stressed calves to all pathogens. Vaccination protocols should be optimized to protect calves from BRD in these anticipated weaning systems.

\section{CONCLUSION}

Early and ultra-early calves presented a wide range of maternally-derived antibody titers against BoHV1, BVDV and BRSV. Vaccination against BoHV-1 was not able to evoke seroconvertion and antibody titers decayed to very low levels at the end of the experience. BRSV specific colostral antibodies were detected in calves, but only a few numbers of animals showed high antibody titers. Seroconversion to BVDV after vaccination could be detected in calves with low antibody titers, while calves with high antibody titers did not develop an active humoral response.

Much of the failure of vaccination may lie in timing of administration, failure of stressed calves to respond properly to vaccination, the multifactorial nature of BRD and the increased susceptibility of stressed calves to all pathogens. Vaccination protocols should be optimized to protect calves from BRD in these anticipated weaning systems.

\section{ACKNOWLEDGEMENT}

The researchers thank to Asociación de Cooperativas Argentinas (ACA) for the financial support and cooperation in this research work.

\section{REFERENCES}

Arthington, J.D., X. Qiu, R.F. Cooke, J.M. Vendramini and D.B. Araujo et al., 2008. Effects of preshipping management on measures of stress and performance of beef steers during feedlot receiving. J. Anim. Sci., 86: 2016-23. DOI: 10.2527/jas.2008-0968

Arthington, J.D., J.W. Spears and D.C. Miller, 2005. The effect of early weaning on feedlot performance and measures of stress in beef calves. J. Anim. Sci., 83: 933-939. PMID: 15753350

Belknap, E.B., J.C. Baker, J.S. Patterson, R.D. Walker and D.M. Haines et al., 1991. The role of passive immunity in bovine respiratory syncytial virusinfected calves. J. Infect. Dis., 163: 470-476. DOI: 10.1093/infdis/163.3.470 
Blanco, M., I. Casasus and J. Palacio, 2009. Effect of age at weaning on the physiological stress response and temperament of two beef cattle breeds. Animal, 3: 108-117. DOI: 10.1017/S1751731108002978

Bolin, S.R. and J.F. Ridpath, 1995. Assessment of protection from systemic infection or disease afforded by low to intermediate titers of passively acquired neutralizing antibody against bovine viral diarrhea virus in calves. Am. J. Vet. Res., 56: 755759. PMID: 7653884

Callan, R.J. and F.B. Garry, 2002. Biosecurity and bovine respiratory disease. Vet. Clin. North Am. Food Anim. Pract., 18: 57-77. PMID: 12064169

Chase, C.C., D.J. Hurley and A.J. Reber, 2008. Neonatal immune development in the calf and its impact on vaccine response. Vet. Clin. North Am. Food Anim. Pract., 24: 87-104. DOI: 10.1016/j.cvfa.2007.11.001

Ellis, J.A., 2001. The immunology of the bovine respiratory disease complex. Vet. Clin. North Am. Food Anim. Pract., 17: 535-550, DOI: 10.1016/j.cimid.2012.01.005

Ellis, J.A., L.E. Hassard, V.S. Cortese and P.S. Morley, 1996. Effects of perinatal vaccination on humoral and cellular immune responses in cows and young calves. J. Am. Vet. Med. Assoc., 208: 393-400. PMID: 8575972

Endsley, J.J., J.A. Roth, J. Ridpath and J. Neill, 2003. Maternal antibody blocks humoral but not $\mathrm{T}$ cell responses to BVDV. Biologicals, 31: 123-125. DOI: 10.1016/S1045-1056(03)00027-7

Endsley, J.J., J.F. Ridpath, J.D. Neill, M.R. Sandbulte and J.A. Roth, 2004. Induction of $\mathrm{T}$ lymphocytes specific for bovine viral diarrhea virus in calves with maternal antibody. Viral Immunol., 17: 13-23. DOI: 10.1089/088282404322875421

Ferella, A., D. Bellido, P. Chacana, A. Wigdorovitz, M.J. Dus Santos and A. Wigdorovitz, 2012. Chicken egg yolk antibodies against bovine respiratory syncytial virus neutralize the virus in vitro. Procedia Vaccinol., 6: 3-3. DOI: 10.1016/j.provac.2012.04.006

Fulton, R.W., R.E. Briggs, M.E. Payton, A.W. Confer and J.T. Saliki et al., 2004. Maternally derived humoral immunity to Bovine Viral Diarrhea Virus (BVDV) 1a, BVDV1b, BVDV2, bovine herpesvirus-1, parainfluenza-3 virus bovine respiratory syncytial virus, Mannheimia haemolytica and Pasteurella multocida in beef calves, antibody decline by half-life studies and effect on response to vaccination. Vaccine, 22: 643-649. DOI: 10.1016/j.vaccine.2003.08.033

Galli, I., A. Monje, S. Vittone, D. Sampedro and C. Busto, 2005. Destete precoz in cría vacuna. Manual para la toma de decisiones there Ejecucion the técnica.
Galli, I., G. Teira, F. Perlo, P. Bonato and O. Tisocco et al., 2008. Animal performance and meat quality in cull cows with early weaned calves in Argentina. Meat. Sci., 79: 521-528. DOI: 10.1016/j.meatsci.2007.10.007

Haley, D.B., D.W. Bailey and J.M. Stookey, 2005. The effects of weaning beef calves in two stages on their behavior and growth rate. J. Anim. Sci., 83: 22052214. PMID: 16100076

Hickey, M.C., M. Drennan and B. Earley, 2003. The effect of abrupt weaning of suckler calves on the plasma concentrations of cortisol, catecholamines, leukocytes, acute-phase proteins and in vitro interferon-gamma production. J. Anim. Sci., 81: 2847-2855. PMID: 14601889

Howard, C.J., M.C. Clarke and J. Brownlie, 1989. Protection against respiratory infection with bovine virus diarrhoea virus by passively acquired antibody. Vet. Microbiol., 19: 195-203. DOI: 10.1016/03781135(89)90066-7

Hulbert, L.E., C.J. Cobb, J.A. Carroll and M.A. Ballou, 2011. The effects of early weaning on innate immune responses of Holstein calves. J. Dairy Sci., 94: 2545-2556. DOI: 10.3168/jds.2010-3983

Lemaire, M., V. Weynants, J. Godfroid, F. Schynts and G. Meyer et al., 2000. Effects of bovine herpesvirus type 1 infection in calves with maternal antibodies on immune response and virus latency. J. Clin. Microbiol., 38: 1885-1894. PMID: 10790117

Lynch, E.M., B. Earley, M. McGee and S. Doyle, 2010a. Characterisation of physiological and immunological responses in beef cows to abrupt weaning and subsequent housing. BMC Vet. Res., 6: 37-37. DOI: 10.1186/1746-6148-6-37

Lynch, E.M., B. Earley, M. McGee and S. Doyle, 2010b. Effect of abrupt weaning at housing on leukocyte distribution, functional activity of neutrophils and acute phase protein response of beef calves. BMC Vet. Res., 6: 39-39. DOI: 10.1186/1746-6148-6-39

Lynch, E.M., M. McGee, S. Doyle and B. Earley, 2012. Effect of pre-weaning concentrate supplementation on peripheral distribution of leukocytes, functional activity of neutrophils, acute phase protein and behavioural responses of abruptly weaned and housed beef calves. BMC Vet. Res., 8: 1-1. PMID: 22217360

Mechor, G.D., C.G. Rousseaux, O.M. Radostits, L.A. Babiuk and L. Petrie, 1987. Protection of newborn calves against fatal multisystemic infectious bovine rhinotracheitis by feeding colostrum from vaccinated cows. Can. J. Vet. Res., 51: 452-459. PMID: 2839276 
Parreno, F., R. Alvarez-Valdes, J.F. Oliveira and J.M. Tamarit, 2010. Neighborhood structures for the container loading problem: A VNS implementation. J. Heuristics, 16: 1-22. DOI: 10.1007/s10732-0089081-3

Platt, R., P.W. Widel, L.D. Kesl and J.A. Roth, 2009. Comparison of humoral and cellular immune responses to a pentavalent modified live virus vaccine in three age groups of calves with maternal antibodies, before and after BVDV type 2 challenge. Vaccine, 27: 4508-4519. DOI: 10.1016/j.vaccine.2009.05.012

Price, E.O., J.E. Harris, R.E. Borgward, M.L. Sween and J.M. Connor, 2003. Fenceline contact of beef calves with their dams at weaning reduces the negative effects of separation on behavior and growth rate. J. Anim. Sci., 81: 116-121. PMID: 12597380

Richeson, J.T., E.B. Kegley, J.G. Powell, P.A. Beck and B.L. Ley et al., 2012. Weaning management of newly received beef calves with or without continuous exposure to a persistently infected bovine viral diarrhea virus pen mate: Effects on health, performance, bovine viral diarrhea virus titers and peripheral blood leukocytes. J. Anim. Sci., 90: 1972-1985. PMID: 22648754

Romera, S.A., L.A. Hilgers, M. Puntel, P.I. Zamorano and V.L. Alcon et al., 2000. Adjuvant effects of sulfolipo-cyclodextrin in a squalane-in-water and water-in-mineral oil emulsions for BHV-1 vaccines in cattle. Vaccine, 19: 132-141. DOI: 10.1016/S0264-410X(00)00104-3

Snowder, G., 2009. Genetics, environment and bovine respiratory disease. Anim. Health Res. Rev., 10: 117-119. DOI: $10.1017 / \mathrm{S} 1466252309990144$
Stilwell, G., M. Matos, N. Carolino and M.S. Lima, 2008. Effect of a quadrivalent vaccine against respiratory virus on the incidence of respiratory disease in weaned beef calves. Prev. Vet. Med., 85: 151-157. DOI: 10.1016/j.prevetmed.2008.02.002

Taylor, J.D., R.W. Fulton, T.W. Lehenbauer, D.L. Step and A.W. Confer, 2010a. The epidemiology of bovine respiratory disease: What is the evidence for predisposing factors? Can. Vet. J., 51: 1095-1102. PMID: 21197200

Taylor, J.D., R.W. Fulton, T.W. Lehenbauer, D.L. Step and A.W. Confer, 2010b. The epidemiology of bovine respiratory disease: What is the evidence for preventive measures? Can. Vet. J., 51: 1351-1359. PMID: 21358927

Valerio, D.A., 2007. Destete precoz e hiper precoz; derrumbando paradigmas. Day E.E.A. INTA Concepción del Uruguay and ACA Animal Nutrition Division.

Vangeel, I., A.F. Antonis, M. Fluess, L. Riegler and A.R. Peters et al., 2007. Efficacy of a modified live intranasal bovine respiratory syncytial virus vaccine in 3-week-old calves experimentally challenged with BRSV. Vet. J., 174: 627-635. DOI: 10.1016/j.tvj1.2006.10.013

Woolums, A.R., R.D. Berghaus, L.J. Berghaus, R.W. Ellis and M.E. Pence et al., 2013. Effect of calf age and administration route of initial multivalent modified-live virus vaccine on humoral and cellmediated immune responses following subsequent administration of a booster vaccination at weaning in beef calves. Am. J. Vet. Res., 74: 343-354. DOI: 10.2460/ajvr.67.7.1179 